\title{
Modeling and Analysis of Ecological Urban Landscape Pattern Evolution Based on Multisource Remote Sensing Data
}

\author{
Zhang Min, ${ }^{1}$ Wang Xuejie ${ }^{(D)}{ }^{1}$ and Liu Yun ${ }^{2}$ \\ ${ }^{1}$ Academy of Art and Design, Anhui University of Technology, Ma'anshan, China \\ ${ }^{2}$ School of Information Engineering, Chaohu University, Chaohu, China \\ Correspondence should be addressed to Wang Xuejie; zm7773@ahut.edu.cn
}

Received 1 May 2021; Accepted 21 May 2021; Published 30 May 2021

Academic Editor: Huihua Chen

Copyright (c) 2021 Zhang Min et al. This is an open access article distributed under the Creative Commons Attribution License, which permits unrestricted use, distribution, and reproduction in any medium, provided the original work is properly cited.

Considering that the development of urbanization cannot be separated from the application of landscape pattern evolution, in order to improve the development level of ecocity, a modeling analysis of ecological urban landscape pattern evolution based on multisource remote sensing data is proposed. Taking ecotype city as the research object, the remote sensing images of ecological urban landscape pattern are screened by using multisource remote sensing data and nonremote sensing data as the basic data. CAMarkov model is constructed and the evolution of ecological urban landscape pattern is analyzed. The experimental results show that, from 2005 to 2020, the development level of urbanization process is higher and higher and the area of building land patches is increasing, which reduces the fragmentation of building land patches. However, the landscape of cultivated land and green space is less and less, and the distribution of the patches also causes uneven phenomenon, which leads to the gradual decline of ecological urban landscape diversity. In the ecological urban landscape pattern, the degree of fragmentation and diversity of urban landscape is reduced due to the high connection and coverage of the construction land.

\section{Introduction}

Due to China's vast territory and large population, energy consumption is increasing. As a result, a series of environmental pollution problems have become more and more serious. The destruction of the ecological environment has caused extreme weather such as drought and high temperature, leading to frequent occurrences of natural disasters. Therefore, the protection of the ecological environment has become the primary issue to realize the sustainable development of mankind [1]. At present, the ecological environment in densely populated urban areas is seriously damaged, and urban green spaces, forests, and water play a decisive role in the entire ecological environment cycle. It can not only purify waste but also regenerate the ecological environment. Therefore, building an ecological urban landscape pattern is an inevitable way to achieve sustainable social development [2]. Therefore, protecting the ecological environment and building an ecological city are the current focus of the Chinese government.
In the process of urbanization, due to the diversification of land use in ecological cities, the landscape pattern of each region is different. There are highly urbanized business districts, urbanized suburbs, and ecological forest land that has not yet been urbanized $[3,4]$. The urban landscape pattern is a witness to the evolution of urban development. It records the traces of urban construction and also reflects the overall style of the city. It is a unique perspective of urban development [5]. As the first large-scale city developed in China, its urban landscape pattern leads to the urbanization process of other cities. The construction of an ecological urban landscape pattern has an important impact on the sustainable development of the city and is the development direction of future urbanization [6].

Based on the above analysis, this paper applies multisource remote sensing data to the modeling and analysis of the evolution of the ecological city landscape pattern, so as to improve the development level of the ecological city. 


\section{Basic Theories and Models of Research}

2.1. The Basic Theory of the Research. The sustainable development of a city is complex system engineering. It involves many aspects such as environment, resources, and mode. The process of urbanization has a huge impact on the types of urban landscapes, which must be combined with the migration of population and the adjustment of industrial structure. The landscape pattern is reasonably evolved. The existing urban landscape pattern is formed through a long process of development and is a manifestation of the harmonious development of nature and mankind. The process of urbanization is the process of transforming ecological land into construction land. After continuous transformation, the urban ecological landscape pattern based on manmade landscape pattern has been formed in the city. Ecotype cities rely on their unique geographical advantages as the forerunners of urbanization, leading to the development of the economy, and the process of urbanization has changed from fast to slow, with a qualitative leap.

Ecocity is used as the research object, and its landscape pattern is modeled and analyzed based on multisource remote sensing data. Ecocity is a sustainable development model that uses environmental resources to realize industrial production and human life [7]. From a narrow perspective, an ecocity is to design the urban landscape pattern according to ecological principles to establish a harmonious, efficient, and healthy human settlement environment [8].

Taking ecological city as the research object, when modeling and analyzing the landscape pattern evolution of ecological city, multisource remote sensing data and nonremote sensing data are mainly used as the basic data [9]. Multisource remote sensing data are core data for interpretation and translation of remote sensing images. Nonremote sensing data are mainly used to assist the interpretation and translation of remote sensing images. The structure of the ecological urban landscape pattern is shown in Figure 1.

After screening the remote sensing images of the ecological urban landscape pattern, the remote sensing images in Table 1 are finally selected as the data source for interpretation.

Nonremote sensing data are used to assist in interpretation of remote sensing images. It mainly includes soil-type maps, land use maps, field survey historical data, administrative division maps, and DEM maps [10], as shown in Table 2.

2.2. CA-Markov Model. CA-Markov model has no aftereffect and can predict the future time state. It is only related to the current ecological urban landscape pattern, not affected by the past state and future state, and the trend is stable. It can better predict the quantity. The simulation results are only quantitative changes, but not embodied in space. The CA-Markov model can predict the quantitative change of ecological urban landscape pattern, generate the suitability of urban landscape pattern as the conversion rule according to multisource remote sensing data, and run the CA module to simulate the future land use spatial distribution pattern in

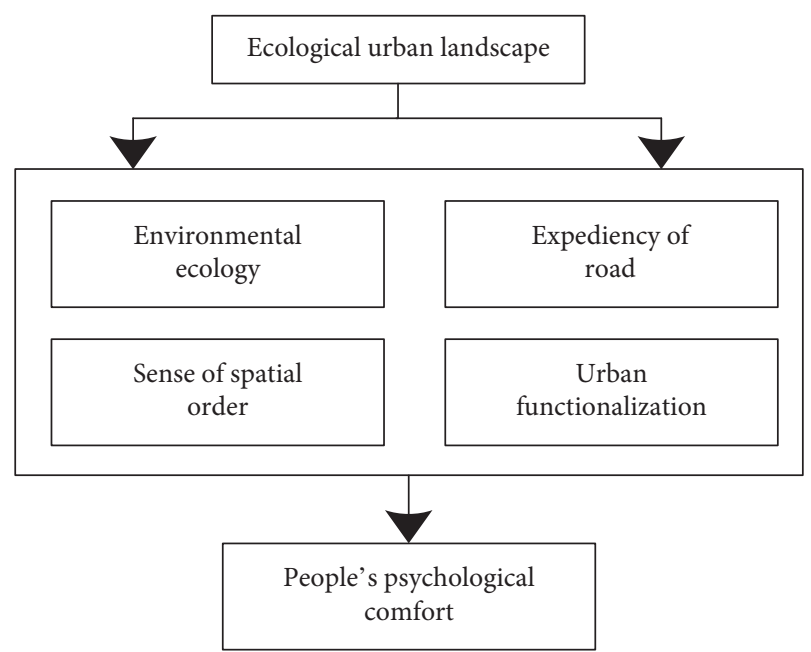

FIGURE 1: Structure diagram of ecological urban landscape pattern.

TABLE 1: Remote sensing image sources.

\begin{tabular}{lcc}
\hline $\begin{array}{l}\text { Landscape } \\
\text { pattern number }\end{array}$ & Satellite type & Remarks \\
\hline $123-32$ & $\begin{array}{c}\text { Landsat5 TM } \\
\text { Landsat7 ETM }\end{array}$ & $\begin{array}{c}\text { The remote sensing image data } \\
\text { come from the geospatial data } \\
\text { cloud platform of the computer } \\
\text { network information center, } \\
\text { and the cloud coverage rate is } \\
\text { less than 5\% }\end{array}$ \\
\hline
\end{tabular}

TABle 2: Nonremote sensing data sources.

\begin{tabular}{lc}
\hline Type of data & Source \\
\hline Soil-type map & Agriculture bureau \\
Land use map & Bureau of land and resources \\
Fieldwork historical data & Historical data \\
Administrative division map & Bureau of surveying and mapping \\
DEM diagram & Geospatial data cloud \\
\hline
\end{tabular}

the study area. The CA-Markov model can make the simulation accuracy of ecological urban landscape pattern land evolution higher. The working principle of the CA-Markov model is that CA is transferred by converting the image of area and probability, thereby simulating the evolution process of urban landscape pattern. The specific operation steps are as follows.

Step 1. The standard for CA model transfer is constructed.

For the same area of a city, urban land use, transportation, and water sources are all important factors that determine the evolution of the urban landscape pattern. These determine the suitability of ecological city construction. Therefore, the image probability image is used to transform the city suitability image.

Step 2. The simulation transition probability matrix is established.

The Markov model is used to simulate the matrix of the transition probability of the urban landscape pattern and the matrix of the transition area. 
Step 3. CA model application.

The CA model is used to break the original landscape pattern model. Combining the weighting factor to recombine, the new urban landscape pattern state can be obtained. The weight factor includes the type, quantity, spatial distribution, and configuration of landscape units in urban landscape pattern. By importing the data of weight factors into the Markov model for analysis, we can get the situation that each weight factor may have a certain type of landscape pattern utilization.

Step 4. The evolution process of the future urban landscape pattern is simulated. The specific flowchart is shown in Figure 2.

Through CA to simulate the fragmentation and reorganization of the urban landscape pattern, the process of the evolution of the urban landscape pattern is simulated.

After the CA simulation, the collected data and modularization can be processed for information fusion. The CA-Markov model is shown in Figure 3.

\section{Specific Implementation Methods}

The landscape pattern index is an important indicator of urban ecological construction, and it is also an important tool for managing urban landscape pattern and monitoring and evaluating it [11]. Based on the landscape pattern index, through the description and analysis of the dynamic changes of the urban landscape, the impact of urbanization on the ecological environment is better understood [12]. Multisource remote sensing data are used to calculate the index of ecological urban landscape pattern. The main content is shown in Figure 4.

The index calculation method and significance of the evolution process of urban landscape pattern are as follows.
3.1. Mean Patch Size (MPS)

$$
\operatorname{MPS}=\frac{A_{i}}{N_{i}} .
$$

In the formula, $A_{i}$ is the total area of landscape green space. $N_{i}$ is the number of green plots in the $i$ landscape. MPS mainly reflects the average fragmentation degree of the landscape.

\subsection{Maximum Plaque Index (LPI)}

$$
\mathrm{LPI}=\frac{\max \left(a_{1}, a_{2}, \ldots, a_{n}\right)}{A} \times 100 \% .
$$

In the formula, $a$ is the green area in a certain area of the city. $A$ is the total area of the landscape pattern of the urban research area. LPI is used to express the percentage of the largest green area of the urban green area to the total area, and the green index can be measured at different levels [13].

\subsection{Plaque Density (PD)}

$$
\mathrm{PD}=\sum_{i=1}^{m} \frac{N_{i}}{A}
$$

In the formula, $m$ is the total number of urban landscape patterns. $N_{i}$ is the number of urban landscape green spaces. $A$ is the total landscape area of the urban study area. PD is used to represent the average fragmentation status of the landscape [14].

\subsection{Contagion Index (CONTAG)}

$$
\text { CONTAG }=\left[\frac{1+\sum_{i=1}^{m} \sum_{k=1}^{m}\left[\left(P_{i}\left(g_{i k} / \sum_{k=1}^{m} g_{i k}\right)\right) \ln \left(P_{i}\left(g_{i k} / \sum_{k=1}^{m} g_{i k}\right)\right)\right]}{2 \ln m}\right] .
$$

In the formula, $P_{i}$ is the proportion of the total green area of the urban landscape pattern; $g_{i k}$ is the number of adjacent sprawl grids from category $i$ to category $k$. CONTAG represents the development trend between urban green space types. The larger the index value, the better the green space types of the urban landscape pattern. On the contrary, the lower the index value, the more scattered the urban landscape pattern and the higher the average degree of fragmentation [15].

\subsection{Fragmentation Index}

$$
\text { DIVISION }=\left[1-\sum_{i=1}^{m}\left(\frac{a_{i}}{A}\right)\right]
$$

The DIVISION index represents the actual situation of fragmentation of the urban landscape pattern. The fragmentation of the green space in the landscape becomes more complicated as the index value increases.

\subsection{Diversity Index}

$$
\text { SHDI }=-\sum_{i=1}^{m}\left(p_{i} \times \ln p_{i}\right) .
$$

In the formula, $p_{i}$ is the total amount of green space in the adjacent urban landscape pattern. When the public boundary of the green space in the urban landscape pattern becomes larger and larger, the degree of fragmentation of the 


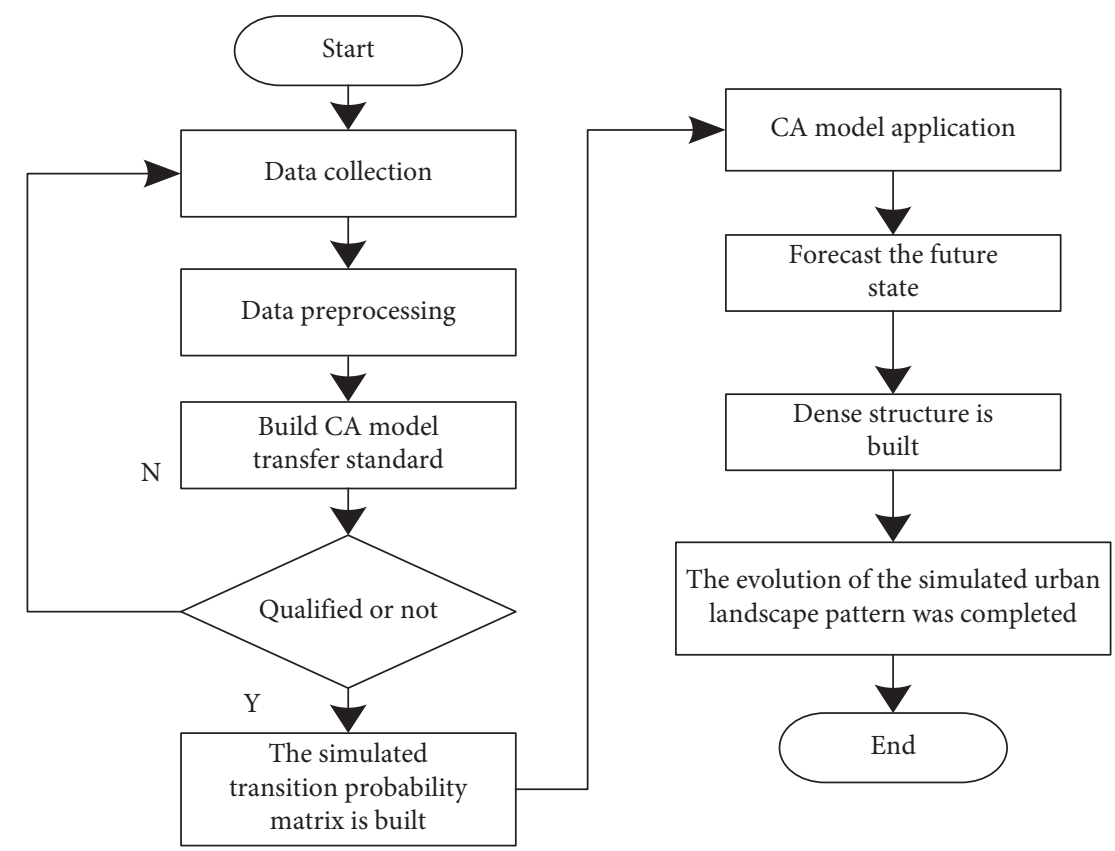

FIGURE 2: Flowchart of the evolution of the simulated urban landscape pattern.

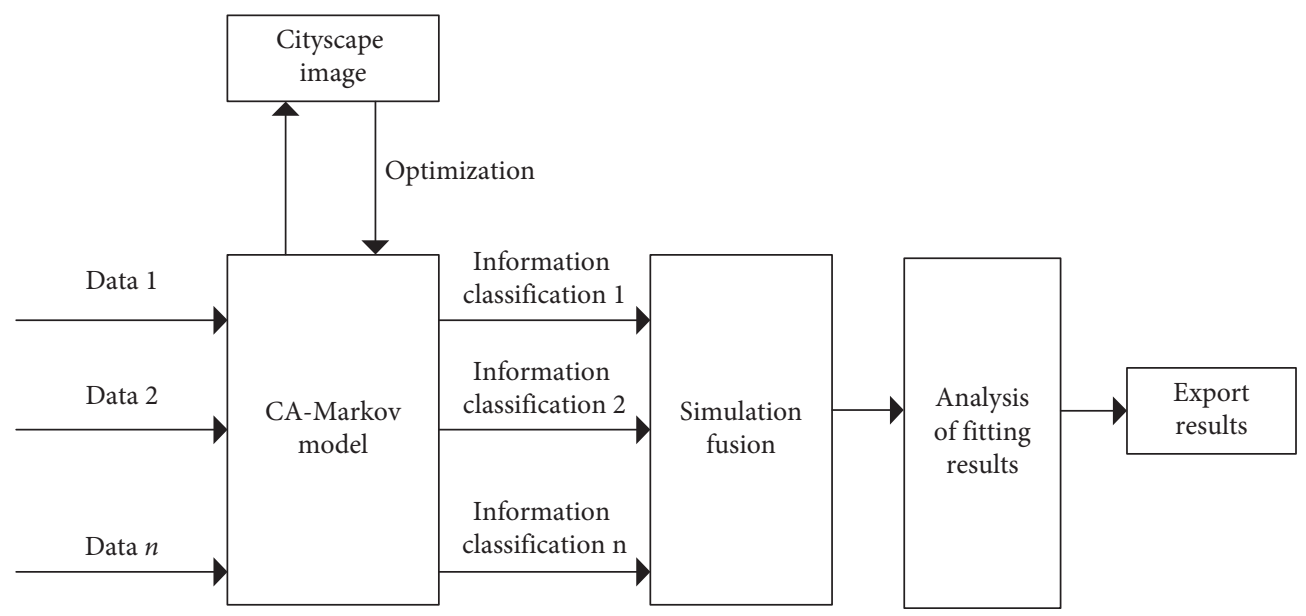

FIgURE 3: Schematic diagram of CA-Markov model.

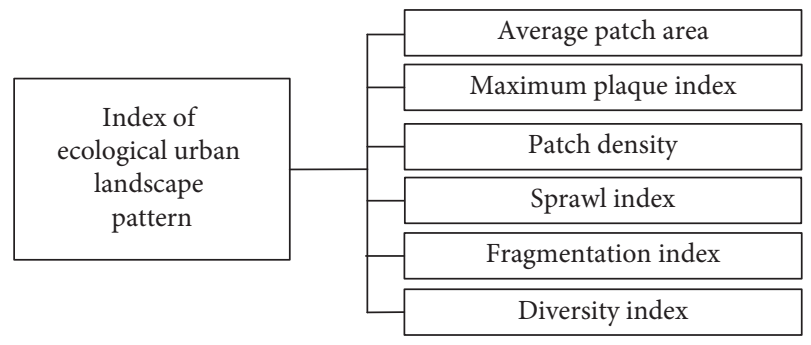

Figure 4: Index structure diagram of ecological urban landscape pattern.

landscape is higher. On the basis of the above indexes, ecological urban landscape pattern renderings are constructed, as shown in Figure 5.

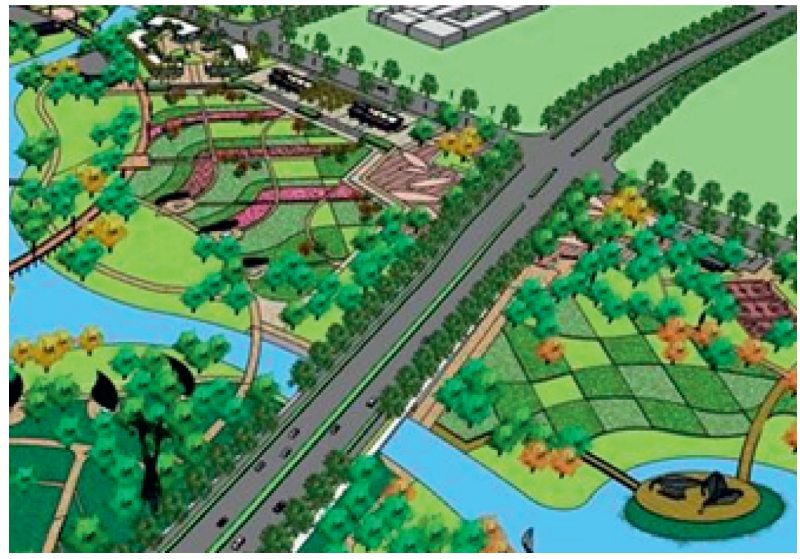

Figure 5: Effect picture of ecological urban landscape pattern. 


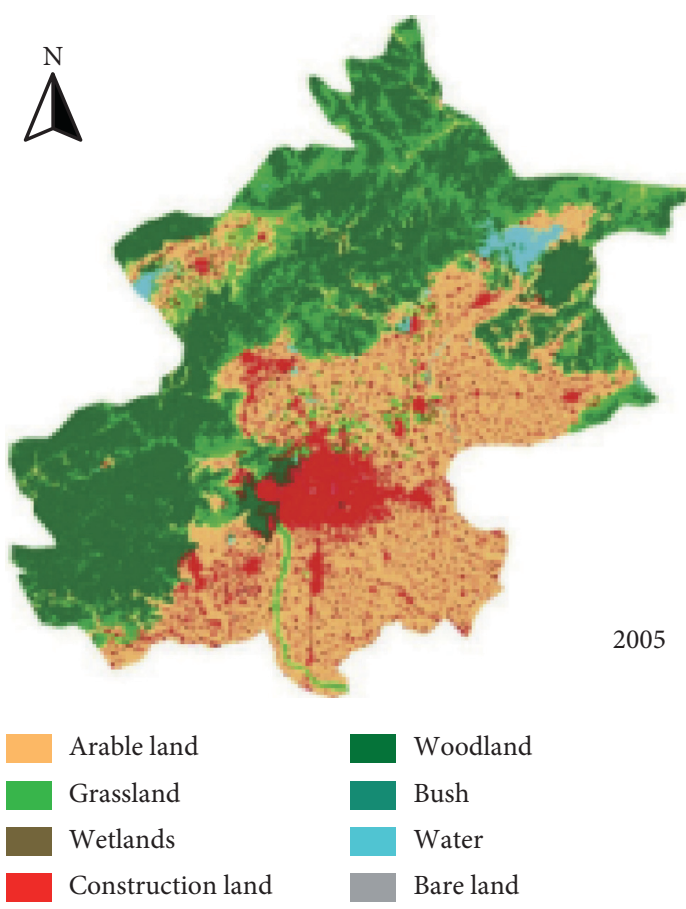

(a)

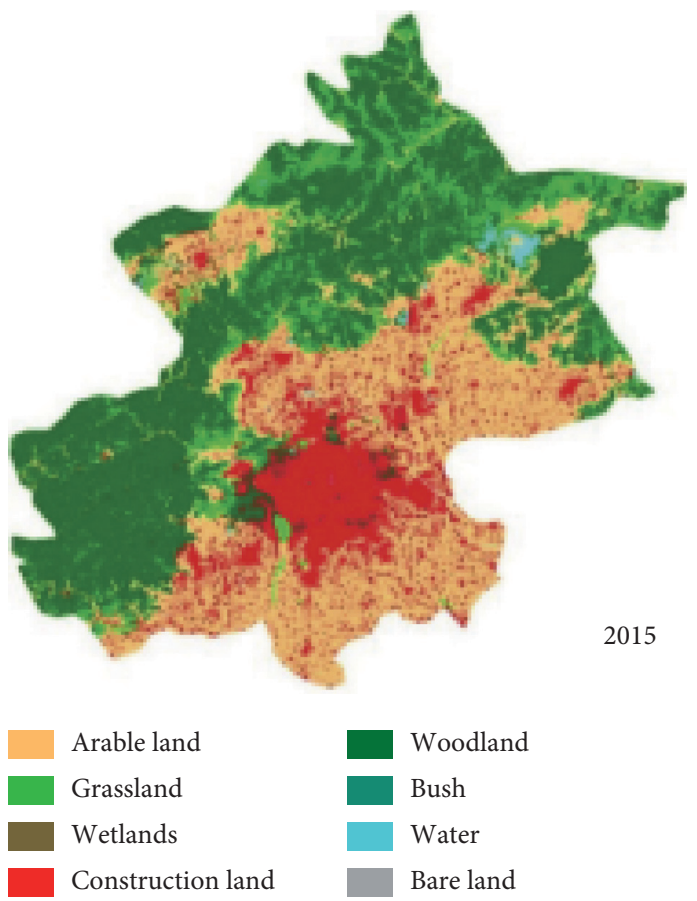

(b)

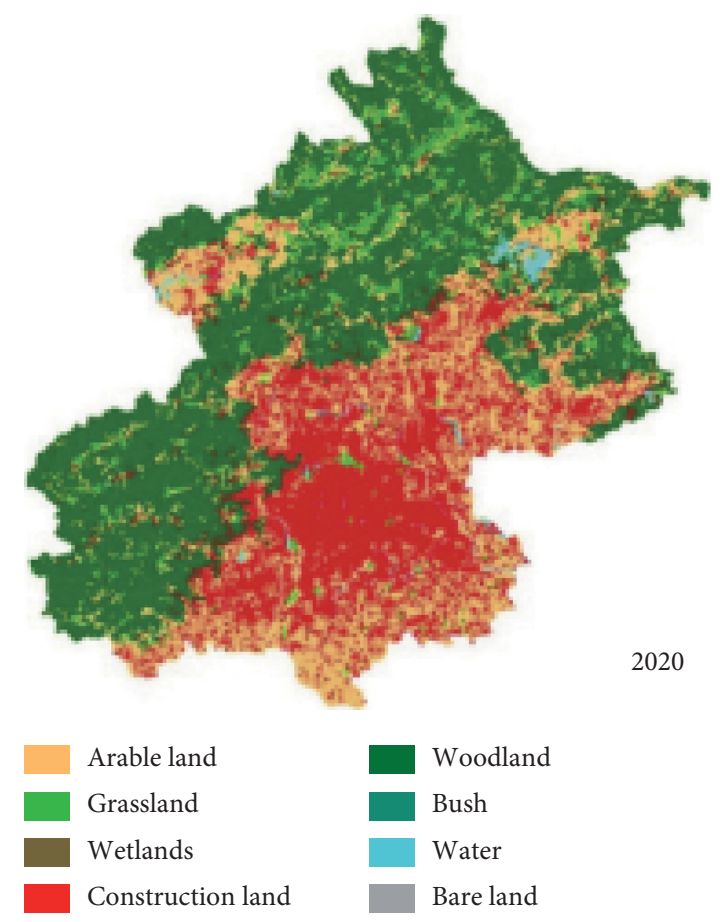

(c)

FIgURE 6: Distribution map of landscape types.

\section{Main Experiments and Analysis}

4.1. Overall Characteristics and Changing Trends of Ecological Urban Landscape Pattern. The distribution of landscape types of ecocity in 2005, 2015, and 2020 is shown in Figure 6.

According to the evolution of the ecological urban landscape pattern in Figure 6, the detailed data and trend of the landscape pattern evolution are formulated, as shown in Table 3.

From the data in Table 3, it can be seen that the composition ratio of the ecological city landscape fluctuates greatly. During the fifteen years from 2005 to 2020, the woodland area of the ecological city exceeds $42 \%$, which has great advantages. . With the development of urbanization and the rapid increase of population, arable land and grassland have 
TABLE 3: The overall composition and changes of the ecological urban landscape pattern.

\begin{tabular}{|c|c|c|c|}
\hline \multirow{2}{*}{ Type of plaque } & \multicolumn{3}{|c|}{ Patch area } \\
\hline & $2005\left(\mathrm{~km}^{2}\right)$ & $2015\left(\mathrm{~km}^{2}\right)$ & $2020\left(\mathrm{~km}^{2}\right)$ \\
\hline Arable land & 5862.27 & 5541.65 & 4526.17 \\
\hline Woodland & 6962.74 & 7062.15 & 7356.63 \\
\hline Grassland & 1592.32 & 1263.47 & 578.60 \\
\hline Bush & 0.26 & 0.26 & 1.97 \\
\hline Wetlands & 7.43 & 13.39 & 31.78 \\
\hline Water & 267.23 & 150.15 & 175.52 \\
\hline Construction land & 1612.44 & 2273.56 & 3632.21 \\
\hline Bare ground & 0.16 & 0.23 & 1.96 \\
\hline \multirow{2}{*}{ Type of plaque } & \multicolumn{3}{|c|}{ Composition ratio } \\
\hline & $2005(\%)$ & $2015(\%)$ & $2020(\%)$ \\
\hline Arable land & 35.9541 & 33.9877 & 27.7597 \\
\hline Woodland & 42.7035 & 43.3132 & 45.1193 \\
\hline Grassland & 9.7659 & 7.7490 & 3.5486 \\
\hline Bush & 0.0016 & 0.0016 & 0.0121 \\
\hline Wetlands & 0.0456 & 0.0821 & 0.1949 \\
\hline Water & 1.6389 & 0.9209 & 1.0765 \\
\hline Construction land & 9.8893 & 13.9441 & 22.2769 \\
\hline Bare ground & 0.0011 & 0.0014 & 0.0120 \\
\hline \multirow{2}{*}{ Type of plaque } & \multicolumn{3}{|c|}{ Change ratio } \\
\hline & 2005 2015 (\%) & & 2015 2020 (\%) \\
\hline Arable land & -1.97 & & -6.23 \\
\hline Woodland & 0.61 & & 1.81 \\
\hline Grassland & -2.02 & & -4.20 \\
\hline Bush & 0.00 & & 0.01 \\
\hline Wetlands & 0.04 & & 0.11 \\
\hline Water & -0.72 & & 0.16 \\
\hline Construction land & 4.05 & & 8.33 \\
\hline Bare ground & 0.00 & & 0.01 \\
\hline
\end{tabular}

become the main sources of ecological urban construction land, so the above three types of landscape changes are the biggest. However, the proportion of construction land has exceeded $10 \%$ and its growth rate is getting faster and faster in the later period. The proportion of cultivated land and grassland pattern has gradually declined, especially the decline of cultivated land. In terms of water area pattern, the proportion has declined slightly but the total area is almost unchanged, which has little impact on the ecological urban landscape. Other patterns can be ignored due to the small base.

4.2. Individual Characteristics and Changing Trends of Ecological Urban Landscape. The maximum patch index is used to measure the dominance of the ecological urban landscape at the patch type level, and the results are shown in Figure 7.

It can be seen from the results in Figures 7 and 8 that woodland has always been a relatively dominant landscape in ecological cities, and this result is completely consistent with the natural environment of ecological cities. The maximum patch index of construction land has risen significantly, with an increase of $8.28 \%$. Therefore, it can be seen that, in ecological cities, construction land has shown a significant growth trend, and the advantages of other landscape types are relatively stable. There is basically no relatively large fluctuation.

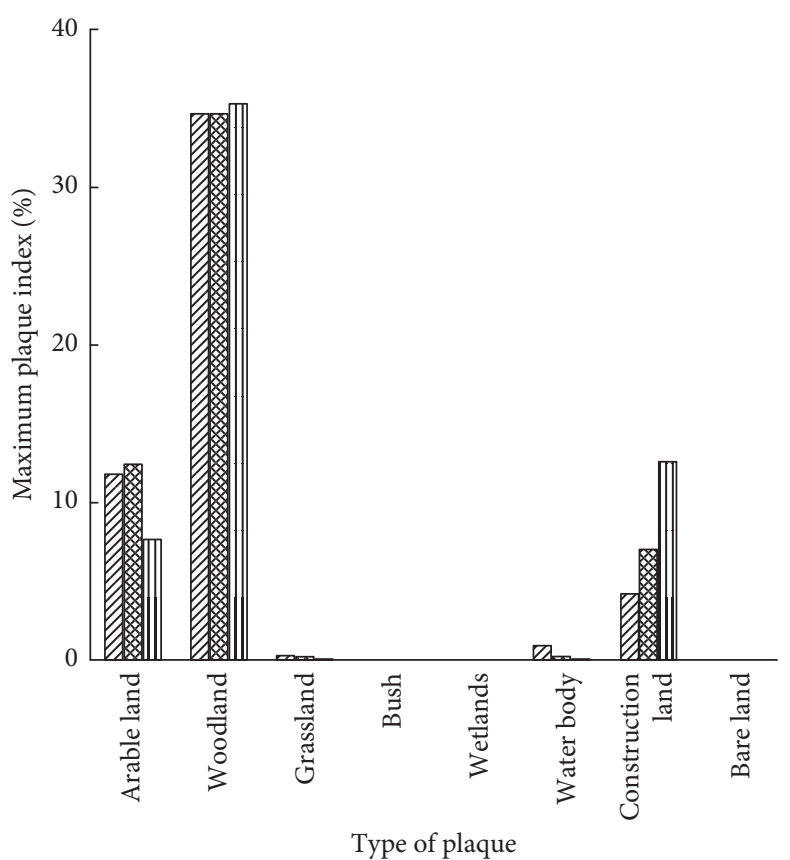

2005
2015
2020

FIgURE 7: Changes in patch types of ecological urban landscape.
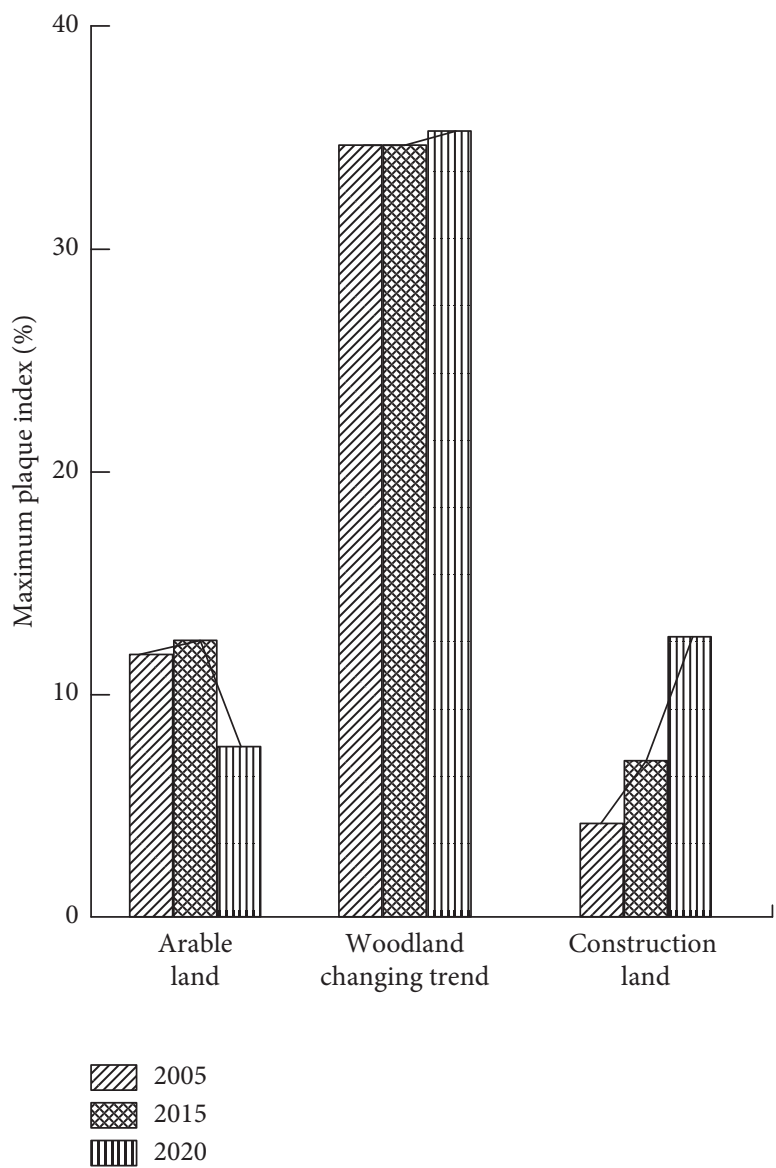

Figure 8: Trend chart of cultivated land, forest land, and construction land. 
TABLe 4: Landscape index of ecological city landscape level.

\begin{tabular}{lccc}
\hline Years & 2005 & 2015 & 2020 \\
\hline Number of plaques & 72884 & 76162 & 76782 \\
Average patch area & $0.2237 \mathrm{~km}^{2}$ & $0.2141 \mathrm{~km}^{2}$ & $0.2124 \mathrm{~km}^{2}$ \\
Sprawl index & 64.5128 & 64.7397 & 65.2860 \\
Separation index & 0.8488 & 0.8488 & 0.8468 \\
Polymerization index & 94.8362 & 94.8392 & 95.7733 \\
\hline
\end{tabular}

TABle 5: Fragmentation index.

\begin{tabular}{|c|c|c|c|}
\hline \multirow{2}{*}{ Type of plaque } & \multicolumn{3}{|c|}{ Number of plaques } \\
\hline & 2005 & 2015 & 2020 \\
\hline Arable land & 858 & 1300 & 1562 \\
\hline Woodland & 12613 & 13634 & 14823 \\
\hline Grassland & 54275 & 56617 & 55120 \\
\hline Bush & 236 & 236 & 251 \\
\hline Wetlands & 67 & 40 & 58 \\
\hline Water & 2496 & 1733 & 1972 \\
\hline Construction land & 2288 & 2546 & 2925 \\
\hline Bare ground & 51 & 56 & 71 \\
\hline \multirow{2}{*}{ Type of plaque } & \multicolumn{3}{|c|}{ Average patch area } \\
\hline & $2005\left(\mathrm{~km}^{2}\right)$ & $2015\left(\mathrm{~km}^{2}\right)$ & $2020\left(\mathrm{~km}^{2}\right)$ \\
\hline Arable land & 6.8325 & 4.2628 & 2.8977 \\
\hline Woodland & 0.5520 & 0.5180 & 0.4963 \\
\hline Grassland & 0.0293 & 0.0223 & 0.0105 \\
\hline Bush & 0.0011 & 0.0011 & 0.0079 \\
\hline Wetlands & 0.1109 & 0.3347 & 0.5479 \\
\hline Water & 0.1071 & 0.0866 & 0.0890 \\
\hline Construction land & 0.7047 & 0.8930 & 1.2418 \\
\hline Bare ground & 0.0032 & 0.0040 & 0.0276 \\
\hline \multirow{2}{*}{ Type of plaque } & \multicolumn{3}{|c|}{ Patch density } \\
\hline & $2005\left(\mathrm{~km}^{-2}\right)$ & $2015\left(\mathrm{~km}^{-2}\right)$ & $2020\left(\mathrm{~km}^{-2}\right)$ \\
\hline Arable land & 5.2636 & 7.9737 & 10.2332 \\
\hline Woodland & 77.3642 & 83.6218 & 89.4116 \\
\hline Grassland & 332.8814 & 347.2428 & 362.0607 \\
\hline Bush & 1.4527 & 1.4526 & 1.5227 \\
\hline Wetlands & 0.4142 & 0.2519 & 0.3602 \\
\hline Water & 15.3126 & 10.6334 & 12.4817 \\
\hline Construction land & 14.0347 & 15.6127 & 14.2113 \\
\hline Bare ground & 0.3118 & 0.3448 & 0.4305 \\
\hline
\end{tabular}

The landscape index of the ecological urban landscape level is shown in Table 4, and the fragmentation index is shown in Table 5 .

It can be seen from the results in Table 4 that the total number of patches of ecological urban landscape was 72884 in 2005 , and it will increase to 76782 in 2020 , reflecting the fragmentation trend of ecological urban landscape.

From the above results, it can be seen that the total number of patches in the ecological urban landscape in 2005 was 72,884 , which increased to 76,782 by 2020 , reflecting the trend of fragmentation in the ecological urban landscape. Cultivated land patch is a landscape with the most obvious changes. Among all landscape patches, it has increased by about $50 \%$, and the average patch area has decreased by about 58\%, resulting in a continuous increase in patch density, which indicates that the cultivated land patches are fragmented. In the ecocity, the environmental carrying capacity has dropped significantly. From 2005 to 2020, the number of patches of construction land has been on the rise, and the average patch area has shown a gradual increasing trend. However, with the advancement of urbanization, construction land has been distributed in a series of landscapes. The patch density of ecocity construction land has a small trend, and the overall urban diffusion and agglomeration are gradually increasing, indicating that the grass patch density is basically unchanged, only the average area is decreasing, indicating that the number of grass patches is increasing, However, it is relatively scattered in the spatial dimension, showing a star-like distribution.

\section{Conclusion}

This paper proposes a modeling analysis of the evolution of the ecological urban landscape pattern based on multisource remote sensing data. Taking the ecological city as the research object, the landscape pattern index and the CAMarkov model are used to quantitatively analyze the evolution of the ecological urban landscape pattern to improve the development level of ecological cities. In ecological cities, the landscape pattern of increasingly higher building land and declining ecological land has a direct impact on the ecological environment of the ecological city. The reason is that the increase in the area of building land has led to increasing drainage pressure in the ecological city. The higher it is, the frequent the occurrence of water logging disasters is; the construction land will also affect the replenishment of groundwater in ecological cities, leading to the emergence of ecological problems. Reducing the ecological land in ecological cities increases the frequency of natural disasters and at the same time affects urban safety.

\section{Data Availability}

The simulation data are used, and the model and related hyperparameters are provided in our paper.

\section{Conflicts of Interest}

The authors declare that they have no conflicts of interest.

\section{Acknowledgments}

This work was supported by the Key Research Projects of Humanities and Social Sciences in Colleges and Universities of Anhui Province (Subject no. RZ2000003385) and also by the Key Research Project of Natural Science in Anhui Province (KJ2019 A0681).

\section{References}

[1] M. A. Hua, Y. Wang, Y. Ning et al., "Dynamic analysis of landscape pattern of the plateau wetland of Zoige County," Forest Resources Management, vol. 33, no. 1, pp. 109-115, 2019.

[2] C. Chulin, H. Wenming, S. Lei et al., "Evolution analysis of forest wetland landscape patterns of rural settlements in the Yangshan area of Haikoucity," Journal of Central South University of Forestry \& Technology, vol. 40, no. 2, pp. 131-141, 2020. 
[3] C. T. Li and C. L. Yunjian, "Changes in landscape pattern of built-up land and its driving factors during urban sprawl," Acta Ecologica Sinica, vol. 40, no. 10, pp. 133-144, 2020.

[4] L. U. Leting, J. Zhang, Q. Peng et al., "Landscape pattern analysis and prediction in the Dongjiang river basin," Acta Ecologica Sinica, vol. 39, no. 18, pp. 6850-6859, 2019.

[5] J. Luo, Z. Sun, and X. Zhang, "Analysis of the characteristics and changes of landscape pattern of oasisin Ganzhou district of Zhangye city based on ripley's K function," Research of Soil and Water Conservation, vol. 26, no. 4, pp. 224-231, 2019.

[6] Y. Hang, X. Cai, Y. Chao et al., "Driving force analysis of landscape pattern changes in Honghu wetland nature reserve in recent 40 years," Journal of Lake Sciences, vol. 31, no. 1, pp. 171-182, 2019.

[7] Y. Wan-Ying, L. Yan-Fang, L. Yao-Lin et al., "Investigating the effect of urban landscape pattern on PM 2.5 concentration based on lur model: a chang-zhu-tan urban agglomeration case study," Resources and Environment in the Yangtze Basin, vol. 28, no. 9, pp. 235-245, 2019.

[8] J. Yuan, W. Chen, B. Du et al., "Analysis of landscape pattern on urban land use based on GF-5 hyperspectral data," Journal of Remote Sensing, vol. 24, no. 4, pp. 465-478, 2020.

[9] J.-J. Wang and B. Gong, "Evolution of landscape pattern and ecological risk in Xixian new area," Journal of Northwest Forestry University, vol. 34, no. 2, pp. 256-262, 2019.

[10] L. Ming-Zhen, Y.-B. Li, and R. Cai-Hong, "Evolution of rural landscape pattern under the background of land use transformation: based on the transect analysis of Caotangxi watershed," Journal of Natural Resources, vol. 35, no. 9, pp. 257-272, 2020.

[11] J. Lei, Z. Chen, Y. Chen et al., "Landscape pattern changesand driving factors analysis of wetland in Hainan island during 1990-2018," Ecology and Environment Sciences, vol. 29, no. 1, pp. 63-74, 2020.

[12] Z. Luo, X. Hu, B. Wei et al., "Urban landscape pattern evolution and prediction based on multi-criteriaCA-Markov model:take Shanghang county as an example," Economic Geography, vol. 40, no. 10, pp. 60-68, 2020.

[13] Y.-Y. Jia, X.-L. Tang, Y. Yang et al., "Landscape pattern changes and ecological service values in Wuhu section along the yangtze river," Journal of Northwest Forestry University, vol. 34, no. 6, pp. 249-258, 2019.

[14] H. Ma, X. Xu, T. Deng et al., "Spatial and temporal evolution of landscape pattern in Jiangdong new area of Haikou city from 1999 to 2018," Journal of Southwest Forestry University, vol. 40, no. 1, pp. 116-123, 2020.

[15] L. Ke-Jun, F. Lu-Ming, X.-B. He et al., "Relationship between forestcity landscape pattern and thermal environment: a case study of Longquan city, China," Chinese Journal of Applied Ecology, vol. 30, no. 9, pp. 186-194, 2019. 